Oral presentation

\title{
Shoe inserts alter inter-segmental foot motion and provide symptomatic relief in patients with midfoot arthritis Smita Rao*1, Judith F Baumhauer ${ }^{2}$, Josh Tome ${ }^{1}$ and Deborah A Nawoczenski ${ }^{1}$
}

\author{
Address: ${ }^{1}$ Ithaca College-Center for Foot and Ankle Research, Rochester, NY, USA and ${ }^{2}$ Department of Orthopaedics, University of Rochester, \\ Rochester, NY, USA \\ Email: Smita Rao* - srao@ithaca.edu \\ * Corresponding author
}

from Ist Congress of the International Foot \& Ankle Biomechanics (i-FAB) community

Bologna, Italy. 4-6 September 2008

Published: 26 September 2008

Journal of Foot and Ankle Research 2008, I (Suppl I):O27 doi:I0.I I86/I757-I I46-I-SI-O27

This abstract is available from: http://www.jfootankleres.com/content/I/SI/O27

(c) 2008 Rao et al; licensee BioMed Central Ltd.

\section{Introduction}

Patients with midfoot arthritis present with disabling pain, which limits their participation in walking and other physical activity. The primary aim of treatment is to afford pain relief and is often attempted using shoe inserts. The custom-molded three-quarter insert (3Q) is recommended as the first line of treatment; however clinical experience shows that patients continue to report pain. Recent reports indicate that the full length carbon graphite insert (FL) may offer symptomatic relief in patients with midfoot arthritis. However the mechanisms by which the FL may be effective remain unknown. The purpose of this study was to examine the effects of four-week intervention with the FL on self-reported outcomes and in vivo intersegmental foot motion in patients with midfoot arthritis.

\section{Methods}

17 patients with midfoot arthritis participated in this study. Mean age: $62 \pm 4$ years, Mean BMI: $29.6 \pm 5.4$ ) 13/ 17 patients were previous users of the $3 \mathrm{Q}$ orthosis. In accordance with IRB and HIPAA guidelines, Informed Consent was sought prior to initiating study procedures. Patients' self-reported outcomes were documented using the Foot Function Index - Revised (FFI-R) prior to and after four week intervention with the FL orthoses.

In vivo segmental foot motion was examined using a 5 segment foot model with previously established validity, as patients walked at self-selected monitored speed ( 0.82 \pm 0.25 and $0.89 \pm 0.19 \mathrm{~m} / \mathrm{s}, 3 \mathrm{Q}$ and $\mathrm{FL}$ respectively, $\mathrm{p}=$ 0.49 ). Modified shoes, with cut-out windows to accommodate the sensors were worn during walking. Local coordinate systems were established by digitizing anatomical landmarks of interest. Kinematic data were low pass filtered using a fourth-order Butterworth filter with a cutoff frequency of $6 \mathrm{~Hz}$ and analyzed using MotionMonitor $^{\mathrm{rM}}$ software. Euler angles, representing three sequential rotations (Z-Y-X) were used to describe joint motion. Peak values for all dependent variables were referenced to subtalar neutral: calcaneal eversion, forefoot abduction, arch dorsiflexion, $1^{\text {st }}$ metatarso-phalangeal (MTP) dorsiflexion. Paired-t tests were used to examine differences between orthoses conditions.

\section{Results}

Four week intervention with the FL orthosis provided symptomatic relief evidenced as 17 and $15 \%$ decrease in pain and activity limitation scores. Improvements were also reflected in total FFI-R score $(36 \pm 10$ and $32 \pm 9$, baseline and after four week intervention respectively, $\mathrm{p}=$ 0.02 ). Compared to the $3 \mathrm{Q}$ orthosis, use of the FL orthosis resulted in increased calcaneal eversion, forefoot abduction and arch dorsiflexion as well as decreased $1^{\text {st }}$ MTP dorsiflexion. (Table 1). 
Table I: Summary of kinematic variables

\begin{tabular}{lccc}
\hline Dependent variable & 3Q & FL & P value \\
\hline Calcaneal eversion & $2.5 \pm 3.0$ & $3.9 \pm 4.2$ & 0.05 \\
Forefoot abduction & $5.9 \pm 8.6$ & $8.3 \pm 9.7$ & 0.10 \\
Arch dorsiflexion & $12.8 \pm 8.2$ & $15.6 \pm 8.1$ & 0.02 \\
| st MTP dorsiflexion & $16.3 \pm 10.9$ & $14.4 \pm 8.2$ & 0.10 \\
\hline
\end{tabular}

Change in pain score was correlated with arch dorsiflexion available in the FL condition $(\mathrm{r}=0.60, \mathrm{p}<0.05)$.

\section{Conclusion}

The findings of this study demonstrate that four-week intervention with the FL affords symptomatic relief in patients with midfoot arthritis. Use of the FL was accompanied by distinct kinematic changes, all of which allowed the foot to assume a lower arched position. Arch dorsiflexion explained a third of the variance in change in pain score. Our findings suggest that kinematic changes, occurring independently or in combination, when using the FL orthoses, result in favorable short-term response to intervention. We hypothesize that kinematic changes in inter-segmental foot motion may influence articular loading and mediate relief of symptoms in patients with midfoot arthritis.

\section{Acknowledgements}

The carbon foot plates used in this study were donated by Wrymark Inc. This work is also supported in part by the Arthritis Foundation and the AOFAS.
Publish with Biomed Central and every scientist can read your work free of charge

"BioMed Central will be the most significant development for disseminating the results of biomedical research in our lifetime. "

Sir Paul Nurse, Cancer Research UK

Your research papers will be:

- available free of charge to the entire biomedical community

- peer reviewed and published immediately upon acceptance

- cited in PubMed and archived on PubMed Central

- yours - you keep the copyright

Submit your manuscript here:

http://www.biomedcentral.com/info/publishing_adv.asp 